\title{
Downpour! - Flood risk communication through interactive immersive street games
}

\author{
Jana Wendler* - Playfuel Games CIC, Manchester, UK \\ Emma L. Shuttleworth - University of Manchester, UK
}

\begin{abstract}
In this paper, we discuss the potential role of immersive interactive games in public engagement with environmental science, in this case flood risk management. Recent high magnitude storm events in the UK have fuelled great public interest in flooding. However, there remains an apparent mismatch between the scientific voice of flooding research and the wider public discourse, which we argue games may be able to address. Downpour! is a street game that casts players as flood risk advisers in a fictional flooding scenario. Players work in teams to respond to an immediate crisis and make longer-term decisions about mitigation through a series of encounters with actors, films, puzzles and treasure hunts. The game was created by a street game designer in collaboration with film-makers, environmental scientists and public institutions, with performances at the Manchester Science Festival and the Festival of Social Science 2016. Based on observations and responses from these events, we discuss how the game fostered understanding of, and engagement with, decision-making in flood risk management. Games offer people the agency to experiment with decisions in a safe space. As a result, we found that players begin to independently interrogate both scientific and political dimensions of flood management. The immersive nature of a street game further creates an emotional connection with the issues, which has the potential for triggering active involvement in flood-related efforts. We conclude by reflecting on the process behind the game creation, commenting on the strengths and difficulties of innovative collaborations between environmental scientists and creative practitioners.
\end{abstract}

Keywords: flooding; science communication; street games; interdisciplinary collaboration

\section{Key messages}

- Street games can advance meaningful and impactful public engagement with environmental science.

- The agency given to players in a game makes complex scientific issues more relatable and therefore accessible.

- A collaborative development process allows scientists to become creative communicators. 
Imagine: it hasn't stopped raining in days and the river banks are collapsing. The risk of flooding is imminent. You and your team of experts have been sent to take immediate action and avert future crises. Can you save the city?

This is the premise of Downpour!, an hour-long street game that casts players as a team of flood risk advisers in Manchester, UK, and faces them with both an immediate crisis and longer-term strategy choices. Throughout the experience, the team of up to five people make choices and receive feedback on their decisions through interactions with actors, bespoke film clips, puzzles, treasure hunts and other mini-challenges. A fictional news broadcast outlines the situation: as waters are rising, the team must take decisions to coordinate priorities and protect vulnerable parts of the city. Having completed this, they are sent to investigate longer-term strategies for flood risk management, from new infrastructure and community responses, to changes in legislation around land management. On their journey, they encounter mayors, lobbyists and buskers; they have to manage budgets and deal with Parliament, before being faced with the largest storm ever to hit the UK. Will their efforts succeed?

\section{Games and science engagement}

The media coverage and political debates surrounding recent storm events in the UK have fuelled great public interest in flooding and climate change (Capstick et al., 2015). Yet there remains a mismatch between the scientific voice of flooding research, the government's flood risk management approach, and public discourse. Members of the public perceive the causes of floods differently to researchers and practitioners, focusing more on local governance issues than on weather and climate factors (Butler et al., 2016). Cologna et al. (2017) further show that political institutions actively promote a sense of security in the way they portray floods as exceptional events and flood defences as complete solutions. This heavily influences the public's perception of flood risk, and not only lowers their preparedness but also unsettles trust in those institutions after flooding occurs. Meanwhile, flood scientists are increasingly aware that local knowledge and expertise play an important role in better understanding community responses to flood events, and thus building local resilience (for example, Lane et al., 2011).

Personal experience has been highlighted as one of the key factors that influences deeper understanding and risk perception (Wachinger et al., 2013), and having a sense of agency, including abilities to effect change and engagement with decision-making processes, has been shown to be a significant factor in improving people's well-being in post-flood contexts (Butler et al., 2016). Consequently, over the past 15 years, there has been much effort put into how best to engage the public in flood science/risk management, with varying degrees of success. Recently, the idea of fostering 'science curiosity' has been put forward as one way of promoting open-minded engagement with scientific information through more creative approaches (Kahan et al., 2017).

Games are an emerging approach to science communication with the potential to stimulate this curiosity and wider engagement (Curtis, 2014), based on their ability to engage people in complex matters through enjoyable and active challenges (McGonigal, 2011). Also known as serious games, with a purpose beyond entertainment, they have gained recognition as their own field in both academic and industry contexts (Ritterfeld et al., 2009). Science games range from being educational in terms of their content or mechanics (for example, Launchball by the Science Museum Group) to utilizing gameplay as a data collection device. A highly successful example of the latter is Foldit, a multiplayer online game that challenges players to manipulate protein 
structures, the results of which have helped to advance algorithms for protein folding predictions (Cooper et al., 2010). Alongside these digital games, we also see a rise of analogue games aimed at educating and empowering players. Many of these make use of role-play mechanics that have been shown to foster complex understanding and collective decision-making in both social and scientific contexts (Resnick and Wilensky, 1998). Games such as the Extreme Event Game, created by Koshland Science Museum, combine these with traditional board-game mechanics such as resource trading to critically interrogate community resilience in disaster scenarios.

The rise in science festivals and similar events takes the emphasis of science communication away from screens and classrooms towards active social experiences in public settings. This shift calls for new interactive formats for science engagement. This coincides with the emergence of street games, also referred to as urban games, as a novel experience format, ranging from city-wide treasure hunts (for example, Citydash by Fire Hazard) to immersive storytelling (for example, Operation Black Antler by Blast Theory). Street games merge the agency and immediacy of games with the physical and immersive nature of interactive theatre. They utilize narrative, media, actors and props to transport players into a highly engaging storyworld within an everyday urban setting. Instead of passively following the action, players navigate this world through their own choices and strategies, based on traditional game mechanics. This might include solving clues to find checkpoints, plotting routes to evade capture or engaging in role-play interaction with characters to advance the game story. Such a set-up fosters a direct emotional engagement with a topic, while providing a space for players to experiment with ideas and solutions. Street games can be played individually, but more often they are team-based. Playing in groups introduces more layered dynamics into the experience, including taking roles and negotiating actions. It is also a practical way of making room for more players and using resources efficiently.

Downpour! utilized this format to examine flood risk management in Manchester. The game was created by Manchester-based game designers Playfuel and filmmakers Oropendola Productions, with input from researchers from the Environmental Processes Research Group at the University of Manchester, and with support from a wide range of organizations. It was presented at the Manchester Science Festival and Festival of Social Science 2016, with 118 attendees. By reflecting on the game and our respective involvement as game designer (Jana Wendler) and flood risk researcher (Emma Shuttleworth), we will make the case for the rich engagement potential of this approach in a broader landscape of research impact and participation in policy.

\section{Street games, agency and engagement}

Street games epitomize the idea of player agency as 'the satisfying power to take meaningful action and see the results of our decisions and choices' (Murray, 1997: 126). The game narrative is blended into the real-world environment, and players directly enact their roles, rather than navigating a character on screen. This creates an immediacy in which game decisions are linked to real-world understanding and action. Creating this sense of agency was a fundamental principle of the research and design behind Downpour!: to offer the players choices that are meaningful both within the story and within a real-life flooding context. When investigating their longerterm strategies, for example, players encounter three laws that they can choose to lobby Parliament to enact: a ban on floodplain development, a revision of farmland management in flood areas, and a ban on grouse shooting in the uplands. These laws, 
which were presented in the form of short caricatured video clips, were derived from issues we had found to be prominent during our research for the game.

Within the game, each law was given a different 'value' regarding flood prevention, based on the effect such a measure would have if implemented on a larger scale. We also assigned a 'controversy level', indicating the level of opposition the law would be likely to face, which we based on the study of literature and news items relating to current real-world debates. A proposition to end floodplain development was given a 'medium' controversy level, while a ban on grouse shooting was of 'high' controversy. The player choice of these laws was embedded in a live interaction with an actor, as well as a mini-game of 'political skittles': persuading the 'parliamentary opposition', to pass the law via the medium of bowling. It is in these moments of decision and play that the power of agency becomes apparent. The choice is not purely hypothetical as in simulation games (that is, 'if you were a flood risk adviser ...'), and it is also more than just a game strategy of gathering the highest number of points. Meaning emerges from the players' active creation of a narrative, based on their personal values, information gathered in the game, and strategies collectively negotiated by the team. Game decisions can therefore transcend the game itself, with effects on real-world understanding and behaviour.

The value of meaningful choice and agency is reflected in the post-game evaluation. We distributed qualitative evaluation sheets, which asked players about moments of learning and other feedback on the game. In their comments, 73 per cent of players stated that they learnt something new about flooding from the game. Most of those learning moments occurred around points of decision-making, such as the one outlined above, with players having gained 'a glimpse of the policies needed to effect real change in the face of climate change' (player comment from written feedback). Players specifically commented on new insights into problematic land management practices, and how, for example, 'the industry associated with grouse shooting damages the ecosystem' (written feedback). We also experimented with ingame reflection, with a 'journalist' character asking teams about their decisions while taking their team picture at the end. These interactions revealed that players were keen to discuss, justify and reflect on their own choices, as well as wanting to find out the best possible paths through the game. While we were not able to fully analyse these comments, we see significant scope here to develop rich qualitative evaluation approaches by embedding them within a game context.

Role-play has previously been highlighted as an effective tool in flood science learning and knowledge exchange in professional settings (McEwen et al., 2014), but this level of immediate engagement from a lay audience was surprising and highly positive. Players saw the game not just as a fun experience, but actively sought further understanding. This included asking deeper questions, such as why the seemingly unrelated practice of grouse shooting has an impact, which gave the team a chance to highlight the link between land management, vegetation cover and storm flow. Other players enquired about local initiatives with which they could get involved, such as volunteer river clean-ups. This final point demonstrates the value of street games as a method of instilling science curiosity. By giving players agency to make decisions regarding real-life issues in an emotionally involving experience, they meaningfully engaged with the subject matter and wanted to learn more. There are, of course, risks and limitations to the format: for one team, the experience did not fully work due to an error in the very tight timing, which is difficult to mitigate while the game is running. The length and extent of the experience also limits the number of players, and requires a prior commitment via a ticketing system. However, as a mode of in- 
depth engagement that aims at both understanding and empowerment, street games such as Downpour! have great value.

\section{Collaboration and the creative process}

We argue that the positive outcomes of Downpour! in terms of player engagement and learning are a direct consequence of the collaborative creative process behind the project. It is increasingly recognized that successful science communication is more than an artistic representation of research results. For example, UK higher education funding bodies require projects to be able to demonstrate the impact of research, defined by HEFCE (2016: n.p.) as 'an effect on, change or benefit to the economy, society, culture, public policy or services, health, the environment or quality of life, beyond academia'. Meaningful art-science collaborations that fulfil this call for impact depend on close and ongoing working relationships between artists and scientists, where projects are co-shaped by different types of knowledge construction (Wienroth and Goldschmidt, 2017).

In the case of Downpour!, Emma and her colleagues played an active role in the creative process around the game, led by Jana as game designer. They provided advice on the science and underlying debates that translated into the decision points of the game. The research phase for the game started with Jana conducting interviews with regional experts from both public bodies and non-governmental organizations, including the Manchester City Council Flood Risk Team and the North West Regional Flood and Coastal Committee. This provided a broad overview but did not give a deeper understanding of the complexity of the science-policy nexus, which was necessary for players to make informed choices. Emma provided this level of insight by sharing findings from existing research projects of significance to the Greater Manchester area, such as Making Space for Water (Shuttleworth et al., in review) and the Howard Street Project (Rothwell et al., 2016). This followed a traditional approach of creative engagement with science, by which researchers provide information and designers develop a creative response.

More unusually, Emma was also critical to the iterative development process. The authors jointly presented a tabletop prototype of the game at the European Researchers' Night event held at the Manchester Museum, which included an option of getting valuable information from a real scientist (Emma). Not only did this framing spark great interest, it further helped the development of the game mechanics and narrative. This presents a novel mode of public engagement for environmental scientists. While there often is a great enthusiasm around outreach work, individuals frequently lack the time, training or opportunity to develop innovative communication and engagement projects on their own (Ecklund et al., 2012). In partnership, however, much more complex ideas become feasible. Scientists taking an active part in artistic performances carve out new roles for creative outreach. As players seek to critically reflect on their experience, having scientists present to discuss current research creates a strong forum of direct two-way communication on an equal footing. Collaboration, therefore, has many facets in art-science projects.

The Downpour! project further illustrates how this collaboration can extend to and include public institutions and policymakers. Downpour! was part of the Climate Lab, a year-long programme run by the Manchester Climate Change Agency (MCCA) to engage people in local climate policy issues and to promote the launch of the city's Climate Change Strategy. MCCA specifically saw it as a mode of reaching beyond their usual circles of publics, and the numbers support that view: only 15 per 
cent of players were previously aware of the Manchester Climate Change Strategy, and almost half had never been to a Science Festival event before. This partnership further attracted support from Manchester City Council and the Greater Manchester Resilience Forum, for whom flooding is a priority area. Although individual contacts between these agencies had been in place before, the novelty and complexity of the street game project provided a common focus for multilateral networking, resulting in new opportunities.

\section{Key messages and recommendations}

The agency afforded by games, combined with the immersiveness of a live interaction, facilitates an emotional experience and critical reflection for players that transcend the game setting and enable active participation in flood risk management. Setting this experience in an accessible urban space and providing room for exchange with environmental scientists further builds links to people's daily lives. At present, the content of the game - its specific choices, controversies and small interactions - is location-specific, in this case tailored to Manchester and the north-west of the UK. Yet the framing - the sequence of interactions and challenges, the metaphors, the balancing and weighting of choices - is mobile, and we can envisage different versions of Downpour! and other street games addressing environmental issues in various local settings. There is further scope to capture the choices and deliberations of players in the game in order to evaluate them and feed options into local flood risk management discussions. This would indicate games as an alternative route for environmental scientists and affected communities to communicate with policymakers and achieve wider participatory policy impact. Close collaborative partnerships between scientists and artistic creators - in this case, game designers - are an essential ingredient for realizing these possibilities.

We see Downpour! as a successful example of how street games can advance meaningful and impactful public engagement on issues of flooding, and environmental science more generally. This in turn makes complex scientific issues more relatable and therefore accessible. It stimulates science curiosity and greatly heightens public visibility of environmental science and scientists, demystifying their role in climate change adaptation and resilience. Alongside this, we demonstrated that the iterative and collaborative development process behind the game provides exciting possibilities for scientists to become creative communicators in their own right.

\section{Acknowledgements}

We would like to thank all the people and organizations involved in creating, playing and sharing the Downpour! game. In particular, thanks go to Oropendola Productions, Manchester Climate Change Agency, the University of Manchester, Manchester City Council, the Manchester Science Festival and the ESRC Festival of Social Science. Thanks also to the three reviewers and associate editor for their positive and constructive comments. The project was supported using public funding by Arts Council England and the Higher Education Innovation Fund Eco-Innovation voucher.

\section{Notes on the contributors}

Jana Wendler is a street game designer with Playfuel Games CIC. Her work focuses on non-digital games with a purpose that address current issues and raise questions. She 
has created street games and playful experience for festivals and events on topics such as immunology, flood management and health data science. She also teaches creative and experimental geographies at the University of Manchester.

Emma L. Shuttleworth is a research associate at the University of Manchester working on the NERC-funded Protect-NFM project (Grant ref: NE/R004560/1). She is a peatland geomorphologist and hydrologist, focusing on how upland restoration can reduce flood risk and provide other ecosystem service benefits. She has a strong track record of partnership working, public engagement and science communication activities.

\section{References}

Butler, C., Walker-Springett, K., Adger, N., Evans, L. and O’Neill, S. (2016) Social and Political Dynamics of Flood Risk, Recovery and Response: A report on the findings of the Winter Floods Project. Exeter: University of Exeter.

Capstick, S.B., Demski, C.C., Sposato, R.G., Pidgeon, N.F., Spence, A. and Corner, A. (2015) Public Perceptions of Climate Change in Britain following the Winter 2013/2014 Flooding (Understanding Risk Research Group Working Paper 15-01). Cardiff: Cardiff University.

Cologna, V., Bark, R.H. and Paavola, J. (2017) 'Flood risk perceptions and the UK media: Moving beyond "once in a lifetime" to "be prepared" reporting'. Climate Risk Management, 17, 1-10.

Cooper, S., Khatib, F., Treuille, A., Barbero, J., Lee, J., Beenen, M., Leaver-Fay, A., Baker, D., Popović, Z. and Foldit Players (2010) 'Predicting protein structures with a multiplayer online game'. Nature, 466, 756-60.

Curtis, V. (2014) 'Public engagement through the development of science-based computer games: The Wellcome Trust's "Gamify Your PhD" initiative'. Science Communication, 36 (3), 379-87.

Ecklund, E.H., James, S.A. and Lincoln, A.E. (2012) 'How academic biologists and physicists view science outreach'. PLoS ONE, 7 (5), Article e36240, 1-5. Online. https://tinyurl.com/y7mkm6ht (accessed 13 November 2018).

HEFCE (Higher Education Funding Council for England) (2016) 'REF impact'. Online. www. hefce. ac.uk/rsrch/refimpact (accessed 28 May 2017).

Kahan, D.M., Landrum, A., Carpenter, K., Helft, L. and Hall Jamieson, K. (2017) 'Science curiosity and political information processing'. Political Psychology, 38 (Supplement 1), 179-99.

Lane, S.N., Odoni, N., Landström, C., Whatmore, S.J., Ward, N. and Bradley, S. (2011) 'Doing flood risk science differently: An experiment in radical scientific method'. Transactions of the Institute of British Geographers, 36 (1), 15-36.

McEwen, L., Stokes, A., Crowley, K. and Roberts, C. (2014) 'Using role-play for expert science communication with professional stakeholders in flood risk management'. Journal of Geography in Higher Education, 38 (2), 277-300.

McGonigal, J. (2011) Reality is Broken: Why games make us better and how they can change the world. New York: Penguin Press.

Murray, J.H. (1997) Hamlet on the Holodeck: The future of narrative in cyberspace. New York: Free Press.

Resnick, M. and Wilensky, U. (1998) 'Diving into complexity: Developing probabilistic decentralized thinking through role-playing activities'. Journal of the Learning Sciences, 7 (2), 153-72.

Ritterfeld, U., Cody, M. and Vorderer, P. (2009) 'Introduction'. In Ritterfeld, U., Cody, M. and Vorderer, P. (eds) Serious Games: Mechanisms and effects. New York: Routledge, 3-9.

Rothwell, J., Stringer, P., Causer, K., Ryan, M., Mangan, S., Appleton, I. and Savage, M. (2016) 'Reducing urban diffuse pollution and surface water flooding using retrofit street trees'. Geophysical Research Abstracts, 18, EGU2016-6177.

Shuttleworth, E.L., Evans, M.G., Pilkington, M., Walker, J. and Allott, T.E.H. (in review) 'Restoration of blanket peat moorland delays stormflow from hillslopes and reduces peak discharge'. Journal of Hydrology.

Wachinger, G., Renn, O., Begg, C. and Kuhlicke, C. (2013) 'The risk perception paradox: Implications for governance and communication of natural hazards'. Risk Analysis, 33 (6), 1049-65.

Wienroth, M. and Goldschmidt, P. (2017) 'Facilitating creative equality in art-science: A methodological experiment'. Leonardo, 50 (1), 42-6. 